\title{
All grown up: A transitional care perspective on the patient with posterior urethral valves
}

\author{
Melise A. Keays, $M D^{\prime}$; Kristen McAlpine, $M D^{\prime}$; Blayne Welk, $M D^{2}$ \\ 'Division of Urology, Department of Surgery, Children's Hospital of Eastern Ontario, University of Ottawa, Ottawa, ON; ${ }^{2}$ Division of Urology, University of Western Ontario, London, ON; Canada
}

Cite as: Can Urol Assoc J 2018;12(4Suppl1):S10-4. hrtp://dx.doi.org/10.5489/cuaj.5228

\section{Introduction}

Posterior urethral valves (PUV) are a familiar entity to most pediatric urologists. The rarity of PUV in the general population makes them an uncommon condition in adult urology, although cases of primary PUV have been diagnosed in adults. ${ }^{1}$ Boys or young men with undiagnosed PUV may present with symptoms of diurnal enuresis $(60 \%)$, urinary tract infections (UTIs) (40\%), urinary straining/pain (10\%), and urinary retention. ${ }^{2}$ PUV is the most common cause of lower urinary tract obstruction in boys, occurring in 1 in 3000-8000 live births. ${ }^{3,4}$ Reduced infant mortality, improved fetal detection, and early treatment of PUV means there is a growing group of young men who were born with PUV. We present an overview of the PUV patient over time and highlight the multiple opportunities to assess and optimize bladder dynamics, decrease infection risk, and ultimately preserve renal function, starting as early as in the womb and into adult life.

\section{Prenatal predictors of long-term outcomes}

Following the widespread availability of prenatal ultrasound beginning in the 1980s, there has been a diagnostic shift where the majority of PUV cases are detected antenatally. ${ }^{5}$ Prenatal ultrasound findings of bladder wall thickening, keyhole sign (dilated posterior urethra), megacystis, and associated hydro-ureteronephrosis are highly sensitive for PUV diagnosis; however, confounding diagnoses, such as bilateral vesicoureteral reflux (VUR), prune belly syndrome, urethral atresia, and obstructing ureterocele may show similar findings. ${ }^{6}$ Prenatal sonographic findings in PUV have been used to predict early fetal and, to some extent, long-term outcomes. Evidence of progressive oligo- or anhydramnios, increased renal echogenicity, and marked bilateral hydronephrosis have been correlated with worse renal and survival outcomes. ${ }^{7-9}$ Antenatal surgical interventions, such as percutaneous vesicoamniotic shunting or cystoscopic valve ablation, ${ }^{10,11}$ have been used in cases of severe lower urinary tract obstruction. These babies typically had oligo- or anhydramnios ${ }^{12}$ and physicians hoped that early bladder decompression would halt progressive renal insult and improve lung development by increasing amniotic fluid levels. Despite poor recruitment, a single randomized trial for prenatal intervention in PUV (PLUTO trial) was completed, showing improved survival in shunted fetuses; however, only one-third of shunted patients had normal renal function at one year of life. ${ }^{10}$ Given the lack of demonstrated long-term improvement in renal function and concerns for adverse events, such as failed procedures, preterm delivery, and fetal demise, ongoing research is required to identify which patients are most likely to benefit from prenatal intervention. ${ }^{10,13}$

\section{Early surgical management}

In cases of suspected PUV, delivery at a high-risk centre is suggested because of potential respiratory complications and the need for access to urological care with early bladder decompression until definitive surgical management. Transurethral valve ablation remains the gold standard treatment for PUV. Once the infant is stable, an endoscopic ablation of valves is performed with a hooked cold knife, resectoscope, electrical bugbee, or laser ablation at the 5, 7, and $12 \mathrm{o}^{\prime}$ clock positions. The vast majority of boys have resolution of upper tract dilation following endoscopic resection. Close attention to renal function, electrolyte balance, and fluid status are also essential in the management of a newborn with PUV. Impaired ability to concentrate urine due to parenchymal damage, polyuria, and hyponatremia are common issues following intervention to relieve the bladder outlet obstruction. ${ }^{15,16}$ Joint care with the neonatal intensive care team and pediatric nephrologists is essential, given the potential complexity of the care for these children.

Adequacy of valve ablation and resolution of VUR is typically assessed with a repeat voiding cysto-urethrogram (VCUG) 4-12 weeks after the initial valve ablation; residual valve tissue requiring re-resection has been reported in $7-15 \%$ of cases in recent series; $;, 17,18$ however, repeat cystoscopy is sometimes required for a more definitive 


\section{Case}

Patient $\mathrm{K}$ was a male born at 37 weeks with antenatal findings of bilateral hydro-ureteronephrosis, a thickened bladder, and oligohydramnios on ultrasound at approximately 35 weeks. Labour was induced due to decreasing amniotic fluid levels. Postnatally, he had respiratory failure due to pulmonary hypoplasia and required short-term intubation and respiratory support. Bladder drainage was initially managed with a 5 French feeding tube. An ultrasound on Day 1 of life demonstrated bilateral Grade 3/4 hydronephrosis, hyperechoic kidneys, a dilated posterior urethra, and a thickened bladder (Fig. 1). A voiding cysto-urethrogram (VCUG) showed a severely trabeculated bladder, bilateral Grade 5/5 vesicoureteral reflux (VUR), and a dilated posterior urethra with evidence of posterior urethral valves (PUV) (Fig. 2). He underwent a cystoscopy, valve ablation, and catheter placement. His elevated renal markers (creatinine $150 \mu \mathrm{mol} / \mathrm{L}$, urea $11.2 \mathrm{mmol} / \mathrm{L}$ ) improved; however, upon catheter removal, there was evidence of incomplete emptying, slight worsening of his hydronephrosis, and an increase in serum creatinine. A vesicostomy was subsequently performed and resulted in improved bladder drainage and improved renal function, with a final nadir estimated glomerular filtration rate (GFR) of $60 \mathrm{ml} / \mathrm{min} / 1.73 \mathrm{~m}^{2}$. During his first two years of life, he had two febrile urinary tract infections (UTIs) due to Escherichia coli and Pseudomonas. He had stable upper tracts and evidence of complete bladder drainage on serial imaging while maintained on antibiotic prophylaxis.

At 2.5 years of age, he was found to void primarily through his urethra, with a small amount of fluid emanating through the patent vesicostomy. Urodynamics performed while the vesicostomy was occluded demonstrated favourable bladder dynamics; a vesicostomy closure was then undertaken. At age seven, he had increasing daytime and nighttime wetting and developed recurrent febrile UTIs. A trial of oxybutynin and intermittent catheterization with overnight drainage was not well-tolerated and he had progression of renal failure to stage 4 chronic kidney disease (CKD). He went on to have bilateral ureteral reimplantations and bladder augmentation with a Mitrofanoff catheterizable stoma. He was closely monitored for advanced CKD until age nine, when he underwent a living related renal transplantation. As a teenager, his care was transitioned to an adult reconstructive urologist for ongoing monitoring of his bladder augmentation and catheterizable channel, and continued followup with transplant nephrology.

assessment. ${ }^{19}$ Beyond residual valve tissue, other long-term complications of early valve ablation include urinary incontinence and urethral stricture formation. ${ }^{20}$

Some patients will require surgical urinary diversion, such as vesicostomy or, very rarely, supravesical urinary diver-

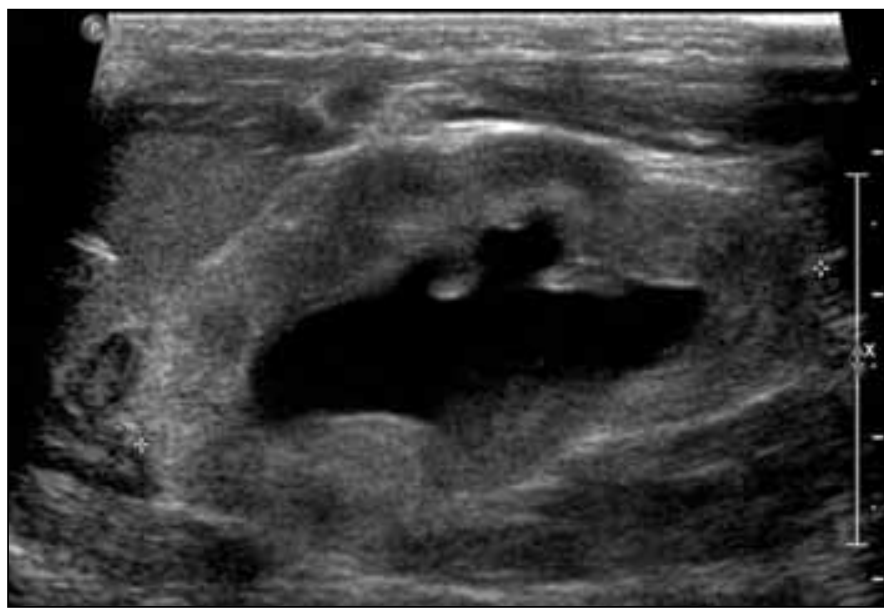

Fig. 1A. Renal and bladder ultrasound on Day 1 of life with bilateral echogenic kidneys and Grade 3 hydronephrosis. sion. Vesicostomy is used for very small infants who cannot undergo primary valve resection, as their urethras cannot accommodate a pediatric resectoscope. There remains con-

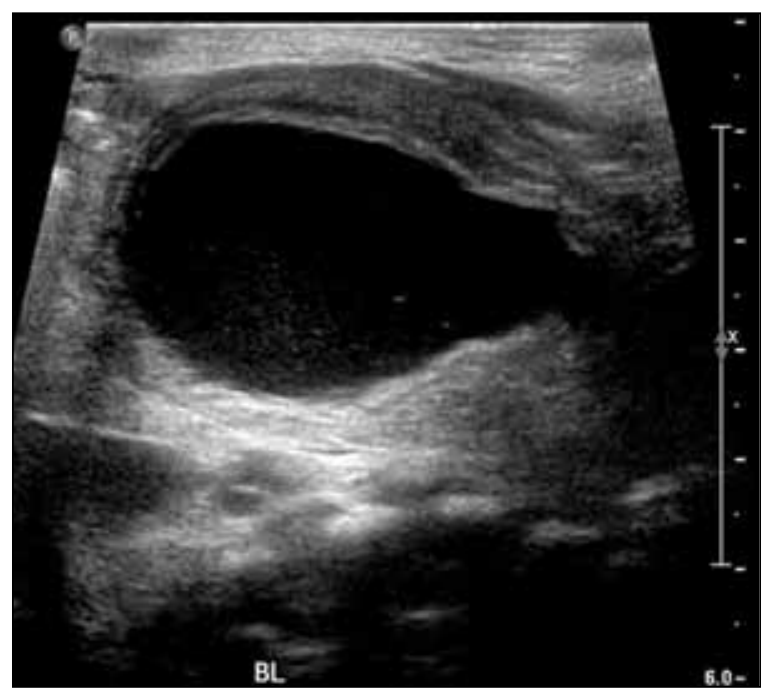

Fig. 1B. Severely trabeculated bladder and dilated posterior urethra seen on ultrasound. 


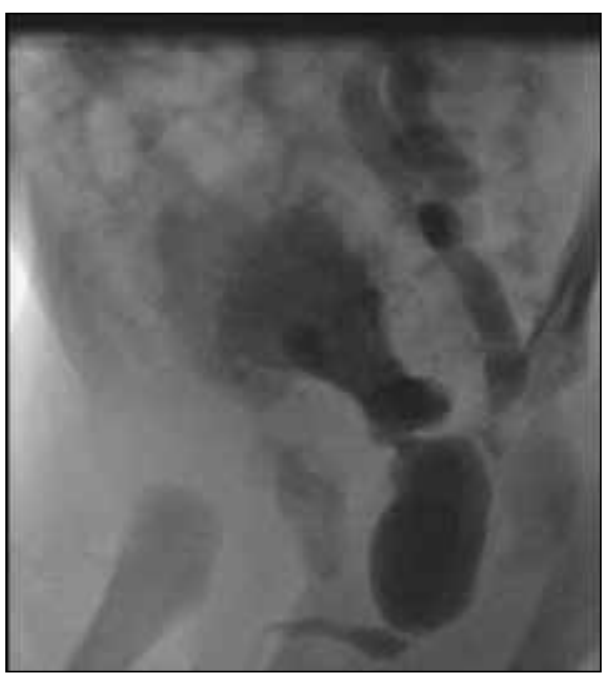

Fig. 2A. Pre-valve incision.

troversy, however, regarding the negative impact of defunctionalizing the bladder. Some studies have demonstrated decreased ultimate bladder capacity and bladder wall compliance in patients with vesicostomy compared to those who underwent a primary valve ablation, ${ }^{21,22}$ while others have shown no detrimental impact on bladder function. ${ }^{23}$

\section{Management issues from childhood to adulthood}

\section{Bladder dysfunction}

Despite early intervention, many PUV patients have inherently abnormal bladders. The term "valve-bladder syndrome" was first described in 1982 by Mitchell. ${ }^{24}$ This syndrome describes persistent bladder dysfunction despite surgically alleviated bladder outlet obstruction. ${ }^{24}$ It is thought to be due to pre-existing bladder changes, including fibrosis, decreased compliance, reduced contractility, and ultimately, myogenic compromise. Clinically, this can present as urinary incontinence or polyuria. Often, children with primary valve ablation will also have delayed onset of continence. ${ }^{25}$ On ultrasound, there may be persistent dilation of upper urinary tracts, a thick-walled non-compliant bladder, and progressive loss of renal function; therefore, bladders of patients with PUV should be assessed with urodynamic studies. ${ }^{26,27}$

During childhood, patients with a history of PUV can have poor bladder compliance, detrusor overactivity, VUR, and uretero-vesical junction obstruction. ${ }^{28}$ These patients are usually classified into one of three groups: 1 ) hyperreflexic; 2) small hypocompliant; and 3) myogenic failure. ${ }^{28}$ Patients with hyper-reflexic and small, poorly compliant bladders are primarily treated with oral anticholinergics, alpha agonists, and/or intravesical onabotulinumtoxinA. ${ }^{29-31}$ Polyuria, defined as hypo-osmolar urine output

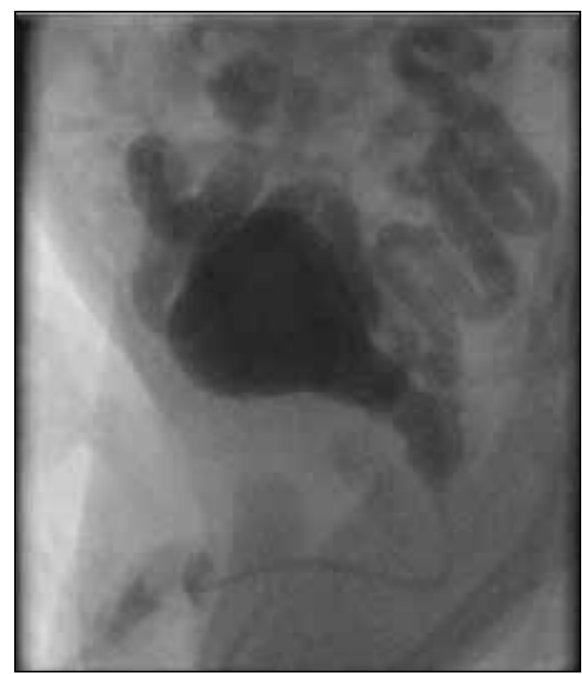

Fig. 2B. Post-incision.

at a volume $>30 \mathrm{cc} / \mathrm{kg} /$ day, can further exacerbate bladder dysfunction. ${ }^{32}$ Polyuria may be treated with overnight catheterization, or nephrectomy for non-functional kidneys. As boys with PUV grow, previously hypercontractile bladders may progress to hypocontractility; ${ }^{33}$ this leads to myogenic failure and overflow incontinence, for which Valsalva voiding and/or clean intermittent catheters may be necessary. ${ }^{34,35}$ Failure in any of these groups will lead to a need for surgical intervention ranging from intradetrusor onabotulinumtoxinA to augmentation cystoplasty with creation of a catheterizable channel. ${ }^{30,36}$

When evaluating a young adult with a history of PUV, it is important to keep in mind that residual bladder symptoms are likely due to detrusor areflexia. ${ }^{37,38}$ Incontinence generally resolves by young adulthood, perhaps due to the growth of the prostate. ${ }^{39,40}$ The etiology of urinary incontinence, if it persists, is likely multifactorial, and may be due to a sphincteric injury at the time of the valve ablation, overflow incontinence, detrusor overactivity, reduced bladder sensation, and nephrogenic diabetes insipidus (DI). In the young adult, nephrogenic DI and the large volumes of urine output may manifest as frequent voiding and nocturia. Differentiation of this condition from a small-capacity bladder or detrusor overactivity can be achieved with a simple frequency-volume chart.

Voiding dysfunction is another common concern in the adult PUV population and a trial of alpha antagonist therapy or a bladder neck incision may be appropriate. ${ }^{41}$ Given the risks of incontinence after a bladder neck incision, careful videourodynamics documenting a voiding phase with a rise in detrusor pressure and a closed bladder neck is necessary to make the diagnosis prior to surgical intervention. A less common reason for voiding dysfunction into adulthood is a stricture secondary to the initial PUV incision. If present, this is often amenable to minimally invasive procedures. ${ }^{20}$ Interestingly, fertility and ejaculatory function seem to be 
preserved among PUV patients, even in those who underwent a bladder neck incision as an infant. ${ }^{40}$

\section{Renal impairment}

A recent systematic review and meta-analysis found that $22 \%$ of patients with PUV go on to develop chronic kidney failure (CKD) and $11 \%$ develop end-stage renal disease (ESRD). ${ }^{42}$ Postnatal predictors of ESRD include the presence of renal echogenicity on the first postnatal ultrasound, ${ }^{8,43}$ a nadir creatinine $>1.0 \mathrm{mg} / \mathrm{dL}$, or ongoing bladder dysfunction in childhood. ${ }^{26,44}$ While persistent VUR or recurrent UTIs during childhood have not been clearly shown to directly increase risk of ESRD in PUV patients, their careful management is recommended to preserve the limited renal reserve. Half of all boys with PUV will have reflux; $25 \%$ of VUR will resolve following valve ablation and $75 \%$ will resolve in the first year of life, most likely for Grades 1-3/5 VUR ${ }^{45-47}$ Consideration of circumcision or antibiotic prophylaxis during the first year of life or for persistent UTIs is certainly reasonable to decrease infection risk. ${ }^{48,49}$

On average, at-risk children progress to ESRD by eight years of age. ${ }^{44}$ Patients who do develop CKD require close monitoring for sequelae of renal failure, including anemia, hypertension, growth disturbances, and hyperparathyroidism..$^{50}$

The risk for further renal deterioration continues into adulthood, primarily as a result of underlying bladder dysfunction and continued renal tubular damage. The fundamental goal of the urologist must be to ensure that the principles of safe bladder management are met (low pressure storage of urine and efficient and safe bladder emptying) to minimize the urological contribution to further renal deterioration. Urodynamics are an important part of this assessment and should be strongly considered for these patients when they present as young adults. ${ }^{41}$ An algorithm for the long-term monitoring and treatment of patients with PUV is available from the European Society for Pediatric Urology. ${ }^{27}$

As PUV patients transition to adulthood, they may require ongoing urological monitoring to ensure their bladder function is safe. Generally, this would include a history, physical exam, voiding diary, serum creatinine, renal imaging, and urodynamics. In the setting of voiding dysfunction, videourodynamics should be used to determine if there is bladder neck dysfunction. Treatment options, analogous to neurogenic bladder patients, are tailored to specific patients and include behavioural modifications, nocturnal bladder emptying (either with an alarm or with temporary catheter drainage), pelvic floor muscle therapy, anticholinergics, intermittent catheters, alpha antagonists/bladder neck incision, and, in select cases, bladder augmentation or reconstruction.

\section{Conclusion}

PUV is a complex, multisystem, chronic condition with varying degrees of bladder and renal impairment. Patients with PUV require intensive intervention at diagnosis and ongoing monitoring for the duration of their lives.

Competing interests: The authors report no competing personal or financial conflicts related to this work.

This paper has been peer reviewed.

\section{References}

1. Köksal IT, Usta M, Erdo ru T, et al. Incidental adult posterior urethral valve without clinical features. Int Urol Nephrol 2003;35:227-9. hitps://doi.org/10.1023/B:UROL.0000020294.84579.04

2. Bomalaski MD, Anema JG, Coplen DE, et al. Delayed presentation of posterior urethral valves: A not so benign condition. J Urol 1999;162:2130-2. https://doi.org/10.1016/S0022-5347(05)68140-2

3. Casale AJ. Early ureteral surgery for posterior urethral valves. Urol Clin North Am 1990;17:361-72.

4. Thakkar D, Deshpande AV, Kennedy SE. Epidemiology and demography of recently diagnosed cases of posterior urethral valves. Pediatr Res 2014;76:560-3. https://doi.org/10.1038/pr.2014.134

5. Warren J, Pike JG, Leonard MP. Posterior urethral valves in Eastern Ontario - a 30-year perspective. Can J Urol 2004:11:2210-5.

6. Bernardes $L S$, Aksnes $G$, Saada J, et al. Keyhole sign: How specific is it for the diagnosis of posterior urethral valves? Ultrasound Obstet Gynecol 2009;34:419-23. https://doi.org/10.1002/vog.6413

7. Mahony BS, Callen PW, Filly RA. Fetal urethral obstruction: US evaluation. Radiology 1985;157:221-4. https://doi.org/10.1148/radiology.157.1.3898218

8. Sarhan OM, El-Ghoneimi AA, Helmy TE, et al. Posterior urethral valves: Multivariate analysis of factors affecting the final renal outcome. J Urol 2011;185:2491-5. https://doi.org/10.1016/i. juro.2011.01.023

9. Matsell DG, YU S, Morrison SJ. Antenatal determinants of long-term kidney outcome in boys with posterior urethral valves. Fetal Diagn Ther 2016;39:214-21. https://doi.org/10.1159/000439302

10. Morris RK, Malin GL, Quinlan-Jones E, et al. Percutaneous vesicoamniotic shunting vs. conservative management for fetal lower urinary tract obstruction (PLUTO): A randomized trial. Lancet 2013;382:1496-1506. https://doi.org/10.1016/S0140-6736(13)60992-7

11. Ruano R, Sananes N, Sangi-Haghpeykar H, et al. Fetal intervention for severe lower urinary tract obstruction: A multicentre case-control study comparing fetal cystoscopy with vesicoamniotic shunting. Ultrasound Obstet Gynecol 2015;45:452-8. https://doi.org/10.1002/vog.14652

12. Farrugia MK, Braun $M C$, Peters $C A$, et al. Report on The Society for Fetal Urology panel discussion on the selection criteria and intervention for fetal bladder outlet obstruction. J Pediatr Urol 2017;13:345-51. https://doi.org/10.1016/i.jpurol.2017.02.021

13. Nassr AA, Shazly SAM, Abdelmagied AM, et al. Effectiveness of vesicoamniotic shunt in fetuses with congenital lower urinary tract obstruction: An updated systematic review and meta-analysis. Ultrasound Obstet Gynecol 2017;49:696-703. https://doi.org/10.1002/vog.15988

14. Churchill B, McLoeiw G, Khoury A, et al. Emergency treatment and long-term followup of posterior urethral valves. Urol Clin North Am 1990;17:343-60.

15. Venglarcik JS, Doerr D, Peden VH, et al. Salt wasting with posterior urethral valves. Pediatr Res 1981;15:515. https://doi.org/10.1203/00006450-198104001-00465

16. Li C, Wang W, Kwon TH, et al. Downregulation of AQPI, -2, and -3 after ureteral obstruction is associated with a long-term urine-concentrating defect. Am J Physiol Renal Physiol 2001;281:F163-71. https://doi.org/10.1152/aprenal.2001.281.1.F163

17. López Pereira P, Urutia Martinez MJ, Jaureguizar E. Initial and long-term management of posterior urethral valves. World J Urol 2004;22:418-24. https://doi.org/10.1007/s00345-004-0460-6

18. Gupta RK, Shah HS, Jadhav V, et al. Urethral ratio on voiding cystourethrogram: A comparative method to assess success of posterior urethral valve ablation. J Pediatr Urol 2010;6:32-6. hitps://doi. org/10.1016/i.jpurol.2009.05.009 
Keays et al

19. Smeulders N, Makin E, Desai D, et al. The predictive value of a repeat micturating cystourethrogram for remnant leaflets after primary endoscopic ablation of posterior urethral valves. J Pediatr Urol 201 1;7:2038. https://doi.org/10.1016/i.purol.2010.04.011

20. Sarhan 0 , El-Ghoneimi $A$, Hafez $A$, et al. Surgical complications of posterior urethral valve ablation: 20 years' experience. J Pediatr Surg 2010;45:2222-6. https://doi.org/10.1016/i.jpedsurg.2010.07.003

21. Podestá ML, Ruarte A, Gargiulo C, et al. Urodynamic findings in boys with posterior urethral valves after treatment with primary valve ablation or vesicostomy and delayed ablation. J Urol 2000;164:139-44. https://doi.org/10.1016/S0022-5347(05)67480-0

22. Puri A, Grover VP, Agarwala $S$, et al. Initial surgical treatment as a determinant of bladder dysfunction in posterior urethral valves. Pediatr Surg Int 2002; 18:438-43. https://doi.org/10.1007/s00383-002-0713-7

23. Kim YH, Horowitz M, Combs $A$, et al. Comparative urodynamic findings after primary valve ablation, vesicostomy or proximal diversion. J Urol 1996;156:673-6. https://doi.org/10.1016/S0022$5347(01) 65781-1$

24. Mitchell ME. Persistent ureteral dilatation following valve ablation. Dial Pediatr Urol 1982;5:8.

25. Smith GHH, Canning DA, Schulman SL, et al. The long-term outcome of posterior urethral valves treated with primary valve ablation and observation. J Urol 1996;155:1730-4. https://doi.org/10.1016/ S0022-5347(01)66186-X

26. Deshpande AV. Current strategies to predict and manage sequelae of posterior urethral valves in children. Pediatr Nephrol 2017:1-11. https://doi.org/10.1007/s00467-017-3815-0

27. Gerharz E, Hoebeke P, Kocvara R, et al. Guidelines on pediatric urology. Urology 2013:67-71. hitps://doi.org/10.1159/000049841

28. Peters $C A$, Bolkier $M$, Bauer $S B$, et al. The urodynamic consequences of posterior urethral valves. J Urol 1990;144:122-6. https://doi.org/10.1016/S0022-5347(17)39388-6

29. Casey JT, Hagerty JA, Maizels M, et al. Early administration of oxybutynin improves bladder function and clinical outcomes in newborns with posterior urethral valves. J Urol 2012;188:1516-20. https://doi. org/10.1016/i.jur. 2012.03.068

30. Mokhless I, Zahran AR, Saad A, et al. Effect of Botox injection at the bladder neck in boys with bladder dysfunction after valve ablation. J Pediatr Urol 2014;10:899-904. https://doi.org/10.1016/i. ipurol.2013.12.023

31. Abraham MK, Nasir ARA, Sudarsanan B, et al. Role of alpha adrenergic blocker in the management of posterior urethral valves. Pediatr Surg Int 2009;25:1113-5. https://doi.org/10.1007/s00383-009-2469-9

32. Koff SA, Mutabagani KH, Jayanthi VR. The valve bladder syndrome: Pathophysiology and treatment with nocturnal bladder emptying. J Urol 2002;167:291-7. https://doi.org/10.1016/S0022$5347(05) 65453-5$

33. De Gennaro $M$, Capitanucci ML, Mosiello $G$, et al. The changing urodynamic pattern from infancy to adolescence in boys with posterior urethral valves. BJU Int 2000;85:1 104-8. https://doi.org/10.1046/ j. $1464-410 x .2000 .00700 . x$

34. Neel KF. Feasibility and outcome of clean intermittent catheterization for children with sensate urethra. Can Urol Assoc J 2010;4:403-5. https://doi.org/10.5489/cuai.955

35. Holmdahl G, Sillén U, Hellström AL, et al. Does treatment with clean intermittent catheterization in boys with posterior urethral valves affect bladder and renal function? J Urol 2003;170:1681-5. https://doi. org/10.1097/01.ju.0000084142.71123.b5
36. King T, Coleman R, Parashar K. Mitrofanoff for valve bladder syndrome: Effect on urinary tract and renal function. J Urol 2014;191:1517-22. https://doi.org/10.1016/i.juro.2013.09.008

37. Holmdahl $G$, Sillén $U$. Boys with posterior urethral valves: Outcome concerning renal function, bladder function and paternity at ages 31 to 44 years. J Urol 2005;174:1031-4. https://doi.org/10.1097/01. ju.0000170233.87210.4f

38. Lal R, Bhatnagar V, Agarwala $S$, et al. Urodynamic evaluation in boys treated for posterior urethral valves. Pediatr Surg Int 1999;15:358-362. hitps://doi.org/10.1007/s003830050599

39. Thomas J. Etiopathogenesis and management of bladder dysfunction in patients with posterior urethral valves. Indian J Urol 2010:26:480-9. https://doi.org/10.4103/0970-1591.74434

40. Keihani S, Kaibafzadeh AM, Kameli SM, et al. Long-term impacts of concurrent posterior urethral valve ablation and bladder neck incision on urinary continence and ejaculation. Urology 2017;99:278-80. https://doi.org/10.1016/i.urology.2016.09.036

41. Glassberg KI, Combs A. The valve bladder syndrome: 35+ years later. J Urol 2016;196:16-7. https://doi.org/10.1016/i.juro.2016.04.049

42. Hennus PML, van der Heijden GJMG, Bosch JLHR, et al. A systematic review on renal and bladder dysfunction after endoscopic treatment of infravesical obstruction in boys. PLoS One 2012;7. https://doi.org/10.1371/journal.pone.0044663

43. Pohl $M$, Mentzel HJ, Vogt $S$, et al. Risk factors for renal insufficiency in children with urethral valves. Pediatr Nephrol 2012;27:443-50. https://doi.org/10.1007/s00467-011-1999-2

44. DeFoor W, Clark C, Jackson E, et al. Risk factors for end stage renal disease in children with posterior urethral valves. J Urol 2008;180:1705-8. htrps://doi.org/10.1016/i.juro.2008.03.090

45. Heikkilä J, Rintala R, Taskinen $S$. Vesicoureteral reflux in conjunction with posterior urethral valves. J Urol 2009;182:1555-60. https://doi.org/10.1016/i.juro.2009.06.057

46. Hassan J, Pope J, Brock III J, et al. Vesicoureteral reflux in patients with posterior urethral valves. J Urol 2003;170:1677-80. https://doi.org/10.1097/01.ju.0000087491.16553.0d

47. Priti K, Rao KLN, Menon P, et al. Posterior urethral valves: Incidence and progress of vesicoureteric reflux after primary fulguration. Pediatr Surg Int 2004;20:136-9. https://doi.org/10.1007/s00383-003$1107-1$

48. Mukheriee $S$, Joshi $A$, Carroll D, et al. What is the effect of circumcision on risk of urinary tract infection in boys with posterior urethral valves? J Pediatr Surg 2009;44:417-21. https://doi.org/10.1016/i. ipedsurg.2008.10.102

49. Bader M, McCarthy L. What is the efficacy of circumcision in boys with complex urinary tract abnormalities? Pediatr Nephrol 2013;28:2267-72. https://doi.org/10.1007/s00467-013-2410-2

50. Sarhan 0 , Nakshabandi $Z$, Alghanbar $M$, et al. Posterior urethral valves: Metabolic consequences in a cohort of patients. J Pediatr Urol 2015;11:216.el-6. https://doi.org/10.1016/i.jpurol.2015.04.022

Correspondence: Dr. Melise A. Keays, Division of Urology, Department of Surgery, Children's Hospital of Eastern Ontario, University of Ottawa, Ottawa, ON, Canada; MKeays@cheo.on.ca 